\title{
Effect of Centre Aisle and Back Veranda for Natural Ventilation in Pontianak Melayu Vernacular House
}

\author{
Tri Wibowo Caesariadi \\ Department of Architecture \\ Engineering Faculty \\ Tanjungpura University, \\ Jalan Ahmad Yani, Pontianak, West Kalimantan, Indonesia \\ Corresponding author: tricaesariadi@teknik.untan.ac.id
}

\begin{abstract}
Vernacular houses are perfect example of environmentally well adapted architecture in Pontianak, Indonesia, which has hot humid tropical climate. The effective way to provide comfort thermal condition in this climate is by optimizing air movement and natural ventilation. Centre aisle and back veranda, found particularly in melayu Pontianak vernacular house, could be considered as special spatial arrangement that was predicted to have been used to create comfortable thermal condition for the house by optimizing natural ventilation performance and this research was done to prove the reliability of such building elements. This was a computed experimental research which used digital model simulation in computer with computational fluid dynamics (CFD) software, FloVENT® 9.1. The experiment emphasized the variation of centre aisle and back veranda to simulate natural ventilation performance in various wind direction (i.e. front, tilted and side perpendicular). The evaluation was determined by assessing the intensity and distribution of air movement within the living spaces. The result of experiment showed that centre aisle and back veranda acted as 'regulators' and also as the airflow controller for other rooms by applying the Bernoulli's principle and venturi tube. This funnel allows living spaces to have comfort natural ventilation, which has airflow velocity less than or equal to $0.5 \mathrm{~m} / \mathrm{sec}$ and distributed evenly spread. The airflow velocity inside living room and bedrooms are $0.78 \mathrm{~m} / \mathrm{sec}$ and 0.05 $\mathrm{m} / \mathrm{sec}$ respectively during front wind direction; $0.52 \mathrm{~m} / \mathrm{sec}$ and $0.40 \mathrm{~m} / \mathrm{sec}$ during tilted wind direction, and $1.04 \mathrm{~m} / \mathrm{sec}$ and $0.98 \mathrm{~m} / \mathrm{sec}$ during side perpendicular wind direction. It is concluded that funnel is important to the natural ventilation performance in melayu Pontianak vernacular house.
\end{abstract}

Keywords: Back Veranda, Centre Aisle, Pontianak Melayu, Natural Ventilation, Vernacular.

\section{Introduction}

Vernacular architecture, which developed along with the social and physical needs of the community. The trial and error process that has been carried out from generation to generation is able to achieve dynamic adjustment conditions for the environment. Thus vernacular architecture can be seen as a very effective solution for the needs of its inhabitants physically due to the demands of environmental conditions (Gutierrez, Luciano, Rodríguez, \& Fink, 2004). One characteristic of vernacular architecture is its climate responsiveness by providing comfort for its inhabitants through passive 
means, one of which is by providing a good thermal environment, which can be attempted through spatial arrangement.

Vernacular architecture of Melayu community of Pontianak also has a distinctive spatial layout. The vernacular house layout of Pontianak Melayu community is divided into a terrace/porch on the front, a living room, and then big centre part which is usually divided and functioned as bedroom, open space or back veranda, and a kitchen in the back (Figure 1).

The typical layout of this house is the existence of centre aisle and open space in back veranda. The centre aisle is usually located in the middle of the building flanked by rows of sleeping rooms on the left and right. The back veranda is an open space that separates the main building (living room, bedroom) and the kitchen. This back veranda is generally without roof but has sidewall as high as up to $2 \mathrm{~m}$.
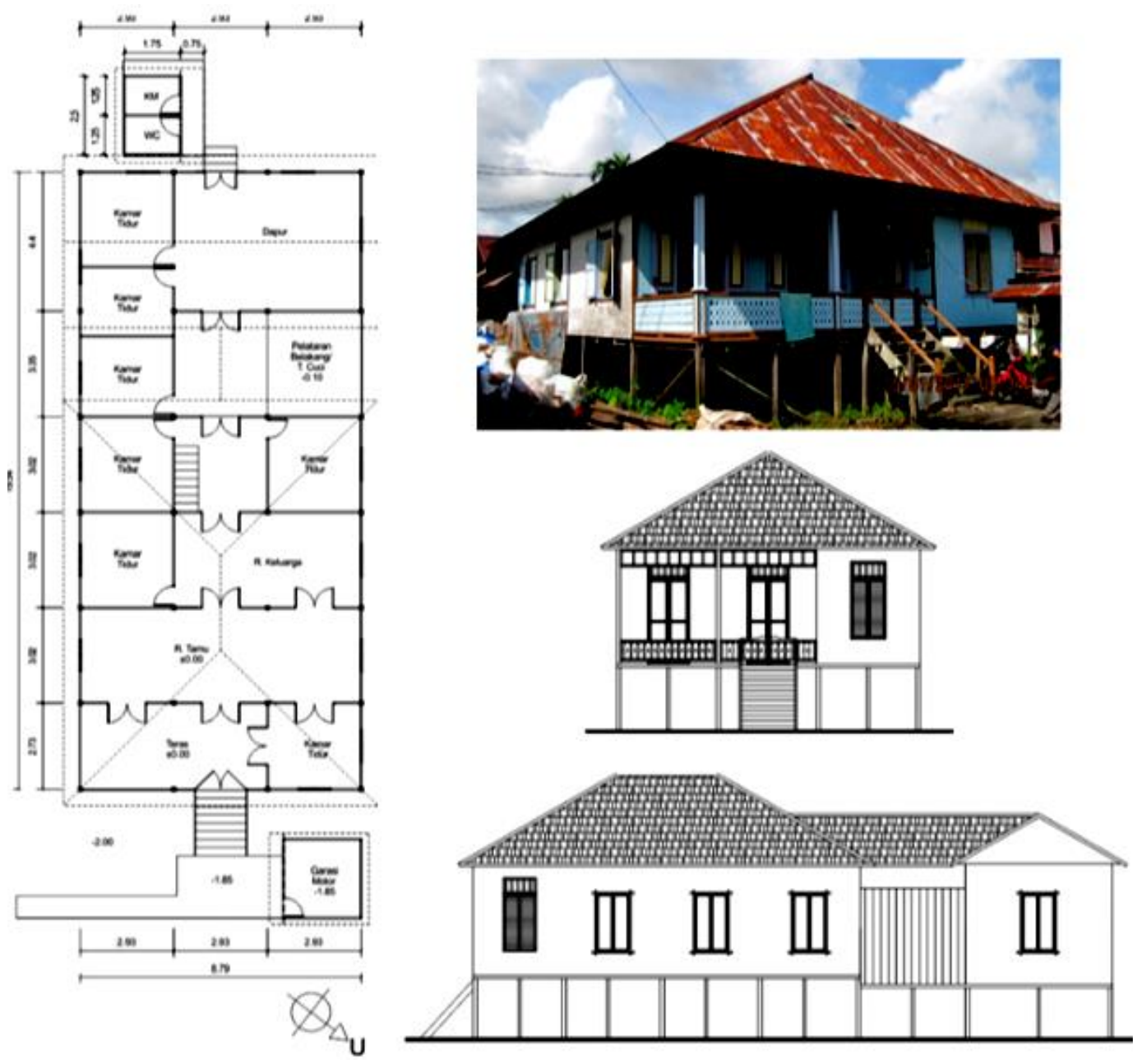

Figure 1 General Form of Typical Pontianak Melayu Vernacular House

Source: Author

Pontianak is located on the equator, on the island of Kalimantan, Indonesia and on a relatively low plain, hence it has the characteristics of wet tropical climate, i.e. high average temperature $\left(32.35^{\circ} \mathrm{C}\right.$ max), high air humidity (86.15\% average), 
with low wind velocity $(2.64 \mathrm{~m} / \mathrm{s}$ average at altitude of $10 \mathrm{~m})$. Thermal environment in Pontianak is generally hot and uncomfortable. The main way to deal with this kind of thermal environment is to seek maximum air movement (Szokolay, 2008; Lechner, 2001; Koenigsberger, Ingersoll, Mayhew, \& Szokolay, 1973). Good air movement and air change will carry out high heat and humidity in the building and replaced by fresh air.

Air temperature is the dominant environmental factor, as it determines convective heat dissipation. The movement of air can accelerate the process of convection as well as the process of evaporation from the skin and produce cooling effect. Air velocity up to $0.5 \mathrm{~m} / \mathrm{s}$ is still felt comfortable, up to $1 \mathrm{~m} / \mathrm{s}$ is felt but with awareness, while above that is felt uncomfortable. But under overheated conditions air velocities up to $2 \mathrm{~m} / \mathrm{s}$ may be welcome (Szokolay, 2008).

Table 1 Subjective Reaction of Air Velocity

\begin{tabular}{cc}
\hline Air Velocity $(\mathbf{m} / \mathbf{s})$ & Reaction \\
\hline$<0.1$ & Stuffy \\
up to 0.2 & Unnoticed \\
up to 0.5 & Pleasant \\
up to 1 & Awareness \\
up to 1.5 & Draughty \\
$>1.5$ & Annoying \\
\hline
\end{tabular}

Source: Author

The nature and character of air movement can be associated with the principles of dynamic fluid. Continuity Equation states that if the fluid flow enters an area with a smaller cross section, then the flow velocity will increase. Thus the difference in dimensions of space passed by air flow will affect its speed (Serway \& Fauqhn, 2005). In the movement of air in buildings, also known as the Venturi effect, if the configuration of a building or space forms a kind of wind tunnel, then the air velocity that passes through it will increase (Melaragno, 1982).

Bernoulli's principle states that increasing the velocity of a flow decreases the static pressure of the flow. This phenomenon causes negative pressure on the hole that shrinks in the venturi tube (Lechner, 2001). Following this principle, the back veranda can also act like a venturi tube as the faster the air flow, the opening between the back veranda and the main building will have negative air pressure which draws air from the main building to the back veranda. 


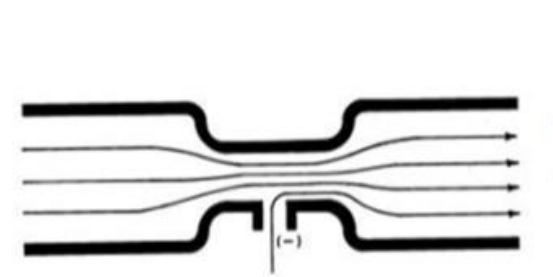

(a)

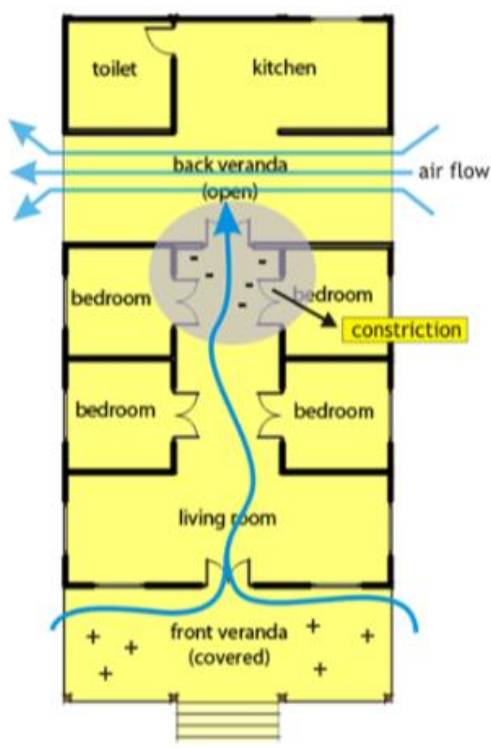

(b)

\section{Figure 2 Comparison Between Venturi Tube (a) with Possibility of Air Flow in Pontianak's Melayu House (b)}

Source: Author

This phenomenon in Pontianak Melayu house has never been observed or proven empirically. By investigating the house layout, it is predicted that the central aisle and back veranda are to support thermal comfort in the building by maximizing air movement. Hence, the main purpose of this study is to find the role of centre aisle and back veranda in determining air movement and the performance of natural ventilation in building.

\section{Research Method}

This study was an experimental computational research that used field measurement data and digital model simulations on computers using computational fluid dynamics (CFD) software, i.e. FloVENT® 9.1 by Mentor Graphics license number 239811, to analyse the velocity and distribution of air movements in building. The research phases consists of simulation of house models in CFD software and quantitative analysis of measurement results. The dependent variables are the intensity of the velocity and distribution of air movement in the back veranda and inside the rooms in the main building. The independent variables are wind direction, width of the centre aisle and back veranda.

\section{Digital Simulation}

Digital simulation was done by using CFD software Flovent ${ }^{\circledR}$ 9.1. which could predict wind movement and distribution. Simulation steps were as follow:

1. Models were built as houses on stilts, with door and window openings as inlet and outlet for wind entrance. All building materials were made of wood (wood block material on FloVENT®), wall thickness of $5 \mathrm{~cm}$ (representing the wood plank 
blades). The models were put inside the virtual wind tunnel with three times bigger volume than the model.

2. The FloVENT® software then calculated the simulation in small parts of the model divided in grids. The grid was determined to be at minimum of $0.4 \mathrm{~m}$ and maximum of $0.5 \mathrm{~m}$ with $\mathrm{V} 3$ smoothing.

3. The type of air flow used was turbulence with the LVEL K- $\varepsilon$ model which is sufficient to be used in the calculation of air flow in open spaces. (FloVENT® User Guide, 2010).

A simulation environment was prepared to adapt the actual environment of Pontianak. Environment variables prepared, based on climate data of Pontianak, were:

- Ambient and radiant temperatures were $30^{\circ} \mathrm{C}$ and air pressure was 1 atm to represent daytime condition

- The wind velocity used was determined based on Pontianak climatology data in 2006-2010 showing the minimum value of the average wind velocity per month, $0.95 \mathrm{~m} / \mathrm{s}$.

- The relative humidity used was $90 \%$

- Other fluid properties were adjusted to conditions of air at the temperatures of $30^{\circ} \mathrm{C}$ and relative humidity of $90 \%$, i.e.:

$\begin{array}{llll}\text { Conductivity } & : 0.02603 \mathrm{~W} / \mathrm{m} . \mathrm{K} & \text { Density } & : 1.148 \mathrm{~kg} / \mathrm{m}^{3} \\ \text { Viscosity } & : 1.833 \times 10^{-5} \mathrm{~N} . \mathrm{s} / \mathrm{m}^{2} & \text { Specific heat } & : 1.1014 \times 10^{3} \mathrm{~J} / \mathrm{kg} . \mathrm{K} \\ \text { Diffusivity } & : 2.206 \times 10^{-5} \mathrm{~m}^{2} / \mathrm{s} & \text { Expansion } & : 3.307 \times 10^{-3} / \mathrm{K}\end{array}$

\section{Building Models}

The basic model for the experiment followed the vernacular Melayu house of Pontianak, i.e. the stilt house with the division of space as shown in Figure 3. The front part was the terrace/porch, the living room, the centre aisle and the bedrooms were also called the main building. The main building and kitchen were separated by an open back veranda. The measuring points were placed spread within $3 \mathrm{~m}$ grids on the front porch, residential spaces (place of activity), i.e. in the living room, centre aisle and bedrooms in the main building, as well as the back veranda and the kitchen. The measuring points in the back veranda were placed in the middle of the width of the building with a distance of $3 \mathrm{~m}$. All measuring points were at a height of $1.5 \mathrm{~m}$ from the floor, which is the height of human activity. The simulation was done on a model with horizontal dimensional variations, which was the width of the centre aisle and the back veranda. The first variation on the width of the back veranda was $2 \mathrm{~m}$ wide (hereinafter referred to as narrow veranda) and $3 \mathrm{~m}$ wide (hereinafter referred to as wide veranda). Then at the width of the centre aisle that was $2 \mathrm{~m}$ wide (hereinafter referred to as narrow aisle) and $3 \mathrm{~m}$ wide (hereinafter referred to as wide aisle). 

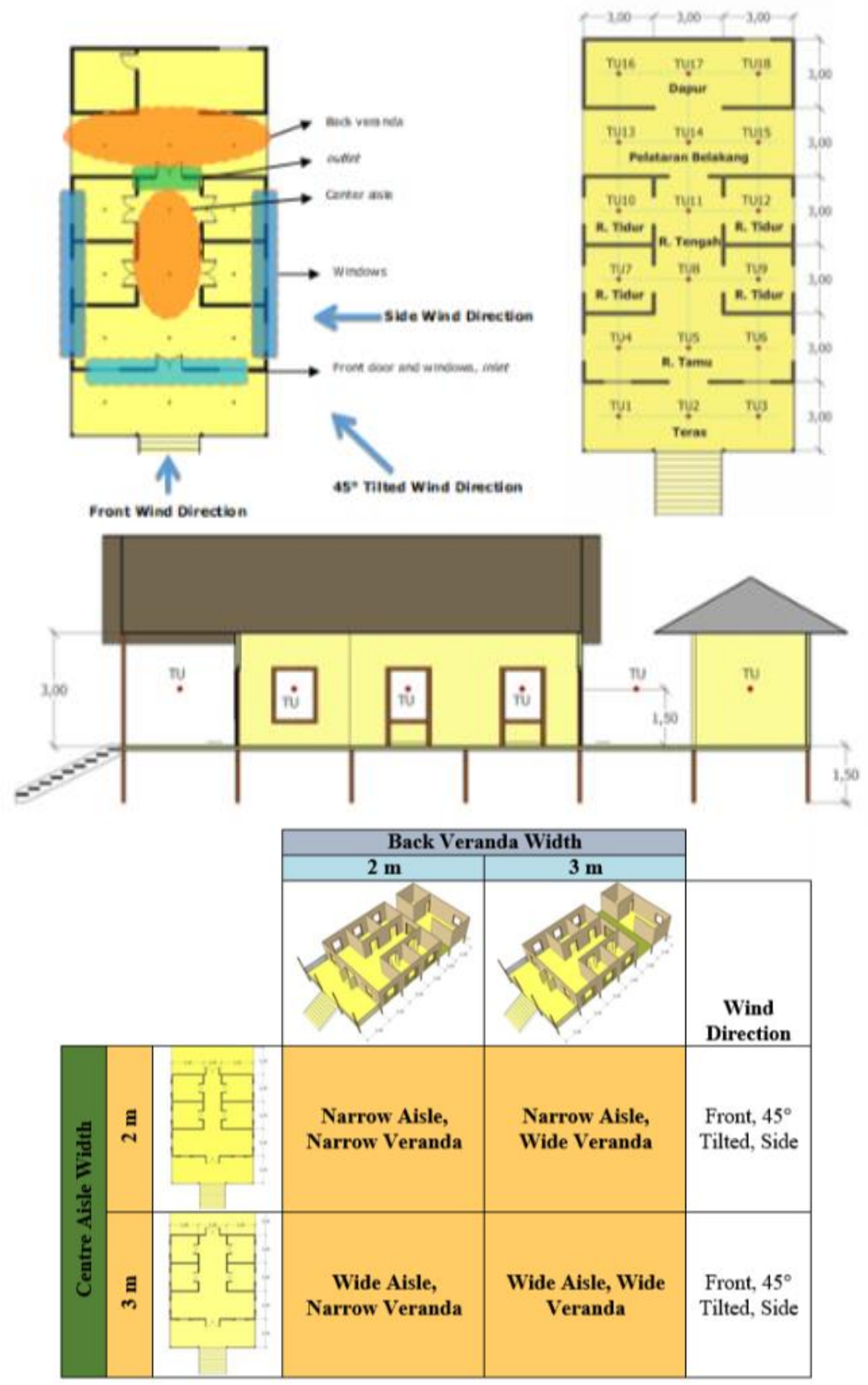

Figure 3 Basic Simulation Model, Measuring Point (TU), Wind Direction Variations and Cetre Aisle and Back Veranda Width Variations for Simulation Purpose

Source: Author 


\section{Result}

\section{Front Wind Direction}

The result showed that the highest air velocity occurred in the centre aisle while the living room still had adequate air velocity $(0.78 \mathrm{~m} / \mathrm{s}$ average $)$, but the bedroom had the lowest unnoticed air velocity $(0.05 \mathrm{~m} / \mathrm{s}$ average $)$. It also showed that higher air velocity in both area occurred with narrow aisle $(0.78 \mathrm{~m} / \mathrm{s}$ in living room and $0.05 \mathrm{~m} / \mathrm{s}$ in bedroom) compared to wide aisle $(0.77 \mathrm{~m} / \mathrm{s}$ in living room and $0.04 \mathrm{~m} / \mathrm{s}$ in bedroom).

Table 2 Average Air Velocity in the Building with Various Models, Front Wind Direction

\begin{tabular}{ccccccc}
\hline & \multicolumn{7}{c}{ Average Air Velocity (m/s) } \\
\cline { 2 - 7 } Models & $\begin{array}{c}\text { Front } \\
\text { Porch }\end{array}$ & $\begin{array}{c}\text { Living } \\
\text { Room }\end{array}$ & Aisle & Bedroom & Veranda & Kitchen \\
\hline $\begin{array}{c}\text { Narrow Aisle - Narrow } \\
\quad \text { Veranda }\end{array}$ & 0.65 & 0.78 & 0.93 & 0.05 & 0.34 & 0.33 \\
$\begin{array}{c}\text { Wide Aisle - Narrow } \\
\quad \text { Veranda }\end{array}$ & 0.65 & 0.77 & 0.98 & 0.04 & 0.35 & 0.41 \\
$\begin{array}{c}\text { Narrow Aisle - Wide } \\
\quad \begin{array}{l}\text { Veranda } \\
\text { Wide Aisle - Wide } \\
\text { Veranda }\end{array}\end{array}$ & 0.65 & 0.78 & 0.93 & 0.05 & 0.2 & 0.31 \\
\hline Average & 0.65 & 0.65 & 0.96 & 0.05 & 0.27 & 0,36 \\
\hline
\end{tabular}

Source: Author

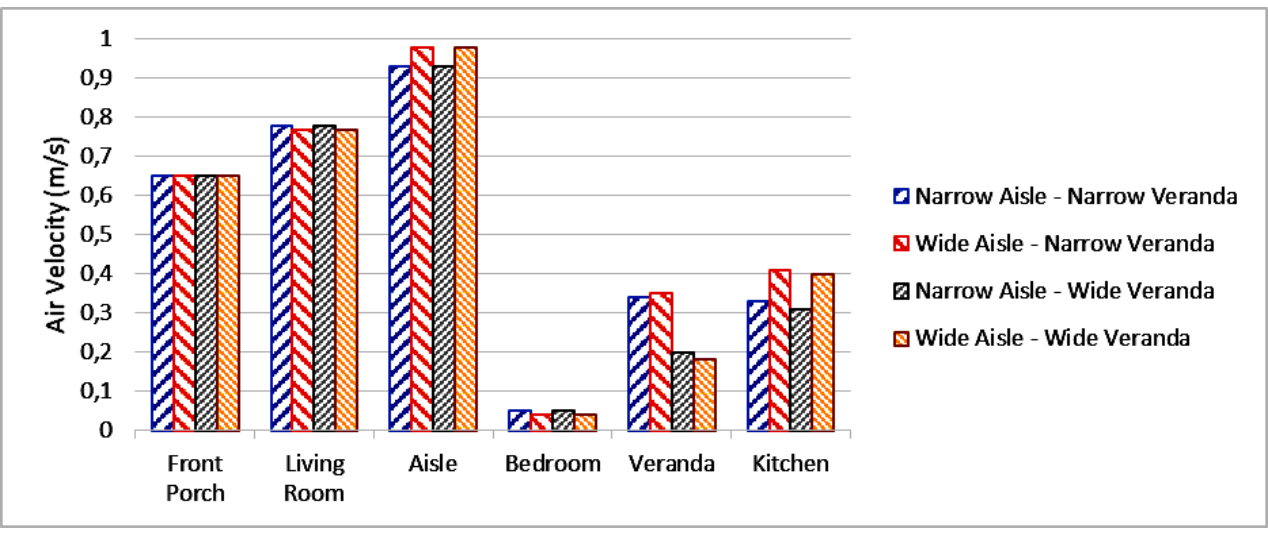

Figure 4 Diagram of Air Velocity in the Building with Various Models, Front Wind Direction

Source: Author

Other phenomenon seen:

- The centre aisle had more role than the back veranda in influencing air movement in residential spaces inside main building.

- The centre aisle could be seen as a tool that generates air movement in the main building because it had the highest air velocity among the other rooms and affected the air velocity of other rooms. In some cases, the air velocity in centre aisle was even higher than outdoor. 
- Wide aisle had a higher air velocity than narrow aisle because the air moved more freely in a wider space. But narrow aisle allowed better air movement in the bedroom because the air moving in the isle was more obstructed so that it looked for a way out to another place, in this case was the bedroom.

\section{$45^{\circ}$ Tilted Wind Direction}

The result showed that the highest air velocity occurred in the back veranda while the living room and bedroom had higher air velocity $(0.52 \mathrm{~m} / \mathrm{s}$ and $0.4 \mathrm{~m} / \mathrm{s}$ average respectively) than previous simulation. It also showed that higher air velocity in both area occurred with wide aisle $(0.52 \mathrm{~m} / \mathrm{s}$ in living room and $0.42 \mathrm{~m} / \mathrm{s}$ in bedroom) compared to narrow aisle $(0.51 \mathrm{~m} / \mathrm{s}$ in living room and $0.38 \mathrm{~m} / \mathrm{s}$ in bedroom).

Table 3 Average Air Velocity in the Building with Various Models, $45^{\circ}$ Tilted Wind Direction

\begin{tabular}{|c|c|c|c|c|c|c|}
\hline \multirow[b]{2}{*}{ Models } & \multicolumn{6}{|c|}{ Average Air Velocity (m/sec) } \\
\hline & $\begin{array}{l}\text { Front } \\
\text { Porch }\end{array}$ & Living Room & Aisle & Bedroom & Veranda & Kitchen \\
\hline $\begin{array}{c}\text { Narrow Aisle - Narrow } \\
\text { Veranda }\end{array}$ & 0.64 & 0.51 & 0.46 & 0.39 & 1.18 & 0.33 \\
\hline $\begin{array}{c}\text { Wide Aisle - Narrow } \\
\text { Veranda }\end{array}$ & 0.64 & 0.52 & 0.5 & 0.43 & 1.16 & 0.41 \\
\hline $\begin{array}{c}\text { Narrow Aisle - Wide } \\
\text { Veranda }\end{array}$ & 0.64 & 0.52 & 0.48 & 0.37 & 1.2 & 0.31 \\
\hline Wide Aisle - Wide Veranda & 0.64 & 0.52 & 0.52 & 0.41 & 1.17 & 0.4 \\
\hline Average & 0.64 & 0.52 & 0.49 & 0.40 & 1.18 & 0.36 \\
\hline
\end{tabular}

Source: Author

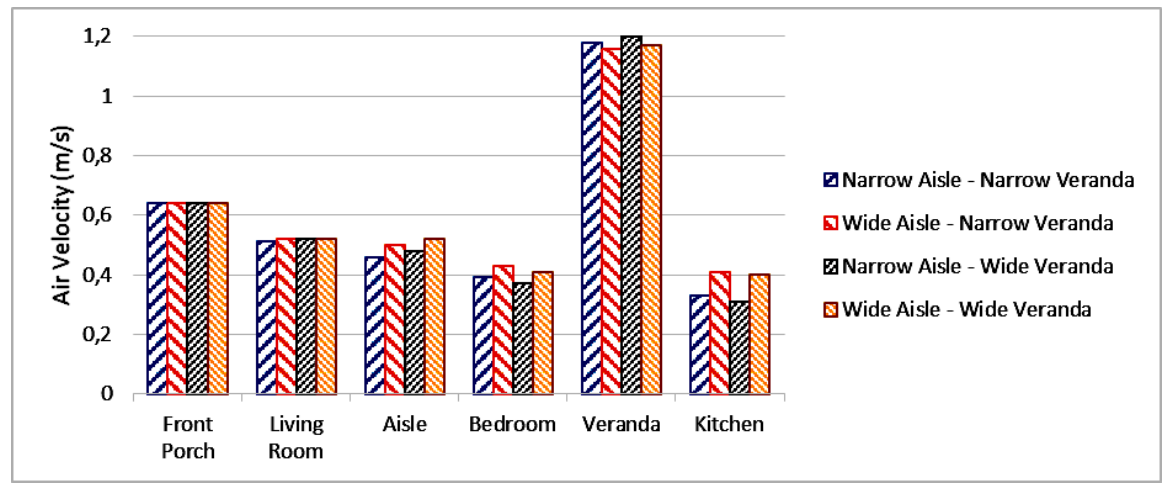

Figure 5 Diagram of Air Velocity in the Building with Various Models, $45^{\circ}$ Wind Direction

Source: Author

Other phenomenon seen:

- The back veranda acted to generate air movement in the main building because it had the highest air velocity among other rooms and influenced air movement in residential spaces.

- Apart from the size of the back veranda, high air velocity in it was caused by the back wall in the veranda which hold back the air movement. Tilted wind that hit this wall was restrained and turned along this wall with increasing speed. 
- The centre aisle functioned more as a transition area of air movement, from the living room to the back veranda and especially from right bedroom to left bedroom. Wide aisle allowed residential spaces to get higher air velocity.

- High air velocity in the back veranda had suction effect on the centre aisle and connected rooms. When air velocity was high, the suction effect was also high, and vice versa.

\section{Side Wind Direction}

The result showed that the highest air velocity occurred in the back veranda while the living room and bedroom also had higher air velocity $(1.04 \mathrm{~m} / \mathrm{s}$ and $0.98 \mathrm{~m} / \mathrm{s}$ average respectively) than previous simulation. It also showed that higher air velocity in both area occurred with wide aisle $(1.05 \mathrm{~m} / \mathrm{s}$ in living room and $1 \mathrm{~m} / \mathrm{s}$ in bedroom) compared to narrow aisle $(1.04 \mathrm{~m} / \mathrm{s}$ in living room and $0.96 \mathrm{~m} / \mathrm{s}$ in bedroom).

Table 4 Average Air Velocity in the Building with Various Models, Side Wind Direction

\begin{tabular}{cccccc}
\hline & \multicolumn{5}{c}{ Average Air Velocity (m/s) } \\
\cline { 2 - 5 } $\begin{array}{c}\text { Models } \\
\text { Narrow Aisle - Narrow }\end{array}$ & $\begin{array}{c}\text { Front } \\
\text { Porch }\end{array}$ & Living Room & Aisle & Bedroom & Veranda Kitch \\
Wide Aisle - Narrow \\
Veranda \\
$\begin{array}{c}\text { Narrow Aisle - Wide } \\
\text { Veranda }\end{array}$ \\
Wide Aisle - Wide Veranda
\end{tabular}

Figure 6 Diagram of air velocity in the building with various models, side wind direction

Source: Author

Other phenomenon seen:

- Almost the entire indoor spaces had higher air velocity than the outdoor. The space that had a relatively equal air velocity with outdoor environment was the centre aisle. 
- The centre aisle functioned more as transition space for wind movement from the right bedroom to the left bedroom. Wider aisles provided higher wind velocity in the bedroom.

- The air distribution occurred tend to be uneven. High air velocity only occurred in the wind movement trail, which was between openings (windows and doors).

- The air velocity in the back veranda also created suction effect for openings along its side. The higher the air velocity, the greater the suction effect was. When the suction effect was large, the air velocity in the main rooms tend to decrease, because the movement of the air was disturbed by the suction effect on the back veranda.

The centre aisle and back veranda have shown the application of the principle of dynamic fluid to optimize air movement in the Pontianak Melayu vernacular house. The Continuity Equation and the Venturi effect which states that the (air) flow velocity will increase when entering a smaller volume space (Serway \& Fauqhn, 2005; Melaragno, 1982) were seen in the centre aisle and back veranda with various wind directions.

In the condition of wind direction coming from the front, the centre aisle became wind movement path that had smaller volume than the previous room (i.e. outdoor, terrace and living room), thus caused the increasing of wind velocity entering the centre aisle. In condition of $45^{\circ}$ tilted wind direction or from the side, back veranda became wind movement path which had smaller volume than previous space (i.e. outdoor), thus caused air velocity in the back veranda to increase. This increase was higher with side wind direction (Figure 7).

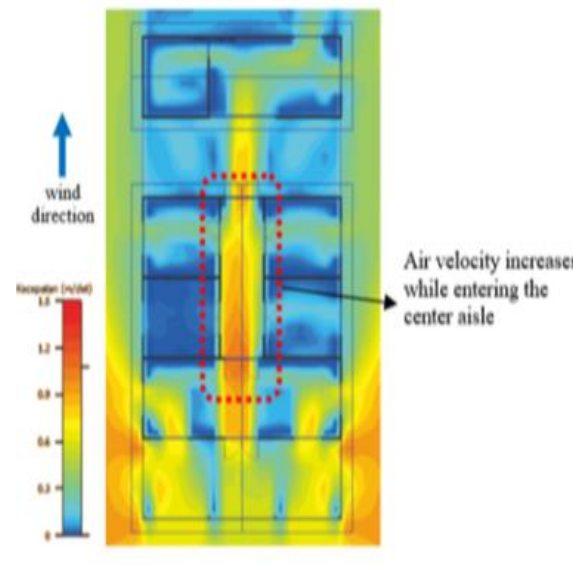

(a)

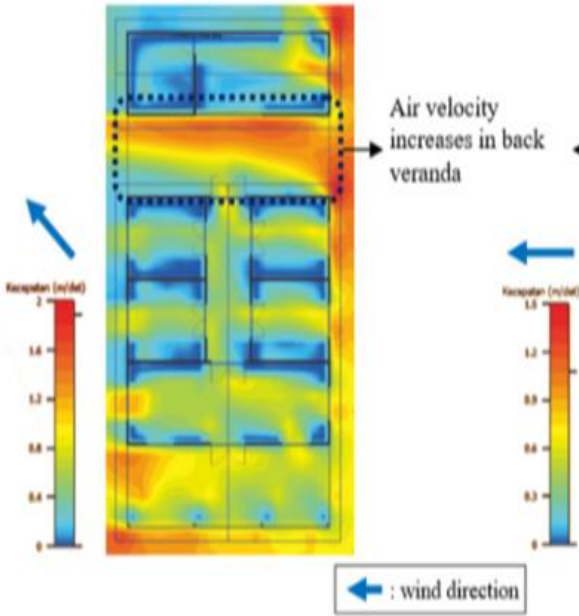

(b)

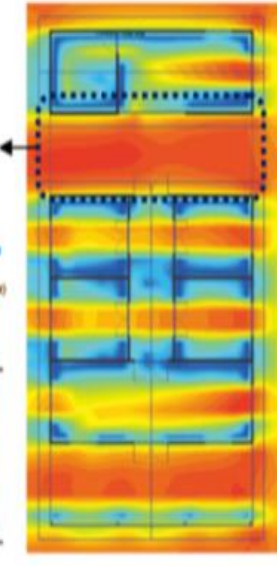

(c)

Figure 7 Air Movement Contour with Various Wind Direction: (a) Front, (b) $45^{\circ}$ Tilted, (c) Side

Source: Author

Bernoulli's principle was seen in the openings between the aisle and the back veranda. Although small, the suction effect in the back veranda caused the air flow from the aisle (and kitchen) to enter the veranda (Figure 8). The suction effect 
indicated a pressure drop in this part which caused air from another place (which has a higher pressure) to move towards the veranda.
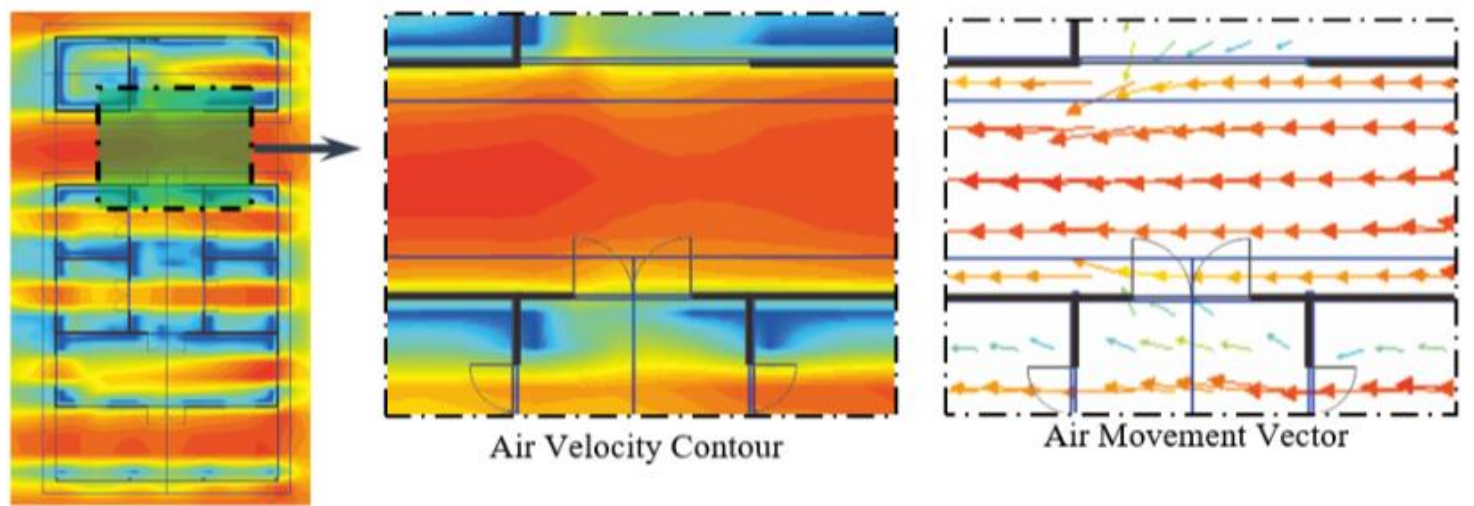

Figure 8 Air Movement Contour with Side and Tilted Wind Direction

Source: Author

\section{Conclusion}

The conclusions obtained regarding the effect of the centre aisle and back veranda on the performance of natural ventilation are:

- The centre aisle and back veranda that act as wind passages function as 'regulators' to the intensity of the velocity and distribution of air flow in the bedrooms and living rooms.

- The width of the centre aisle influences the velocity and distribution of air flow in the bedrooms and living rooms. This can be seen when the wind comes from the front (Table 2), the centre aisle serves as a provider of air velocity for the bedroom, and a narrower aisle gives a higher velocity than a wider aisle, thus acted like venturi tube.

This study showed that the vernacular architecture of Pontianak Melayu house had applied the principles of dynamic fluid to obtain optimal natural ventilation. This proves the reliability of vernacular architecture as an example of architecture that adapts to its environment and is sustainable architecture. However, some limitations faced include the ability of the software used (i.e. FloVENT ${ }^{\circledR} 9.1$ ); other elements of building which could be considered such as stilt floor, ceiling or roof material, were not included due to time and budget limitation; and other Pontianak Melayu vernacular house layout that might exist.

\section{Acknowledgments}

I would like to thank Dr. Surjamanto Wonorahardjo, lecturer of Bandung Institute of Technology and head of Building Science Laboratory of ITB who has given guidance and support during the study. I am grateful also to Emilya Kalsum, MT, lecturer of Department of Architecture, Tanjungpura University, for helpful comments and critics. 


\section{References}

Gutierrez, O., Luciano, M. C., Rodríguez, M., \& Fink, B. (2004). Comparison between an acceptance-based and a cognitive-control-based protocol for coping with pain. Behavior Therapy, 35(4), 767-783.

Koenigsberger, O. H., Ingersoll, T. G., Mayhew, A., \& Szokolay, S. V. (1973). Manual of tropical housing and building, part one: climatic design. London: Longman Group Limited.

Lechner, N. (2001). Heating, cooling, lighting: design methods for architects. New York: John Wiley \& Sons, Inc.

Melaragno, M. (1982). Wind in architectural and environmental design. New York: Van Nostrand Reinhold Company.

Serway, R. A. \& Fauqhn, J. S. (2005). College Physics. (7 ${ }^{\text {th }}$ e.d.). Belmont: Thomson Brooks.

Szokolay, S. V. (2008). Introduction to architectural science: the basis of sustainable design. ( $2^{\text {nd }}$ e.d.). Oxford: Architectural Press Elsevier. 